\title{
TO BE BLACK AND ALIVE: A STUDY OF THE INHERENT RACISM IN THE TERTIARY EDUCATION SYSTEM IN POST-1994 SOUTH AFRICA
}

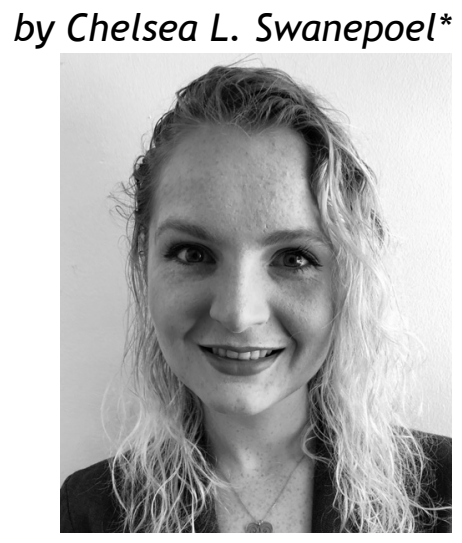

\section{Introduction}

The second decade of the 21st century has seen an increase in pressure on tertiary institutions across the globe to dramatically transform. This call has, to a large extent, been spearheaded by the Fees and Rhodes Must Fall Movements that began in South Africa in 2015, however, decolonial thought and African resistance to colonialism has been present since the birth of colonialism itself. ${ }^{1}$ Initially, the Rhodes Must Fall movement called for the removal of a statue of the imperialist slave owner, Cecil John Rhodes, and the 'uncritical memory of his legacy' with it, but this movement soon developed into cross-country protests of colonial bias, racism, and black exclusion in university settings. ${ }^{2}$ Similar calls for the

* Third year BA Law student majoring in English with a passion for the role of language and literature in daily life. In conducting research for this paper, I came across the spoken word poem by Crystal Valentine and Aaliyah Jihad titled: 'To be black and woman and alive' which comments on the paradoxical existence of black people and in particular, black women in society. This comment on identity and its application in a post-colonial university setting inspired this paper and holds true to its focus.

1 TK Ranuga 'Frantz Fanon and black consciousness in Azania (South Africa)' (1986) 47(3) Phylon at 186. See also B Kwoba, R Chantiluke \& A Nkopo. 'Rhodes must fall in Oxford' in Rhodes must fall: the struggle to decolonise the racist heart of empire (2018) 3.

2 Kwoba, Chantiluke \& Nkopo (n 2) 3. 
transformation of curricula were heard at Oxford in which the residual colonial legacies left by Rhodes and his contemporaries were labelled as the root cause of epistemic injustice in academia and were called to be removed. ${ }^{3}$

Since this movement, academics have, to a certain extent, had a consciousness of the need for the inclusion of both African and feminist thought across various faculties. At the University of Pretoria, Critical Race and Gender Theory have been adopted as a part of an elective module in the LLB program, the English department has started to include African texts from a first-year level, and the first black female doctor of Philosophy, Dr Mpho Tshivhase, has been employed as a lecturer of morality and ethics. ${ }^{4}$ Universities across South Africa have also undertaken the process of renaming spaces to be better represent the various cultures of the student body, as well as reviewing language policies. ${ }^{5}$ Despite these attempts at transformation, many have argued that their effect on the substantive decolonisation of South African academia has been merely superficial and that the ingrained and systematic racism and Eurocentrism of the university system has failed to be radically addressed. ${ }^{6}$

While many argue that science, academia and the law should be logical, objective and neutral, there are various debates surrounding first, whether such an objective is possible and second whether it is desirable. ${ }^{7}$ Historically, one can see that academics largely reflect upon the values of the society in which they operate and, in doing so, manifest a particular bias and prejudice precluding thought from being neutral. In Western academics, this bias is categorised as both racial and Christian in the construction of an image of the rest of the globe as a distinct 'other' in need of 'civilization'. ${ }^{8}$ Not only were scientific theories dismissed on the grounds of contradicting the Christian Bible, but they have also been fabricated or twisted into theories of pseudoscientific biology to justify racism and white supremacy. ${ }^{9}$ Though, for the most part, this mode of thought has been

3 Kwoba, Chantiluke \& Nkopo (n 2) 4.

4 JSM Modiri 'The grey line in-between the rainbow: (Re)thinking and (re)talking critical race theory in post-apartheid legal and social discourse' (2011) 26 South African Public Law at 178.

5 University of the Free State v Afriforum and Another 2018 (2) SA 185 (CC) para 3.

6 Modiri (n 4) 177-178.

7 VY Mudimbe Power and otherness in the invention of Africa: gnosis, philosophy and the order of knowledge. (1988) 20-21.

8 Horton, R 'Chapter 12' in African philosophy: A classical approach P English and KM Klumba (eds) (Prentice Hall: New Jersey 1996) 197-199. See also K Wiredu 'Conceptual decolonization as an imperative in contemporary African philosophy: Some personal reflections' (2002) 36 Rue Descartes, at 56.

9 N Eltringham, “'Invaders who have stolen the country': The Hamitic hypothesis, race and the Rwandan genocide,' (2006) 12(4) Journal for the Study of Race, Nation and Culture at 426. 
criticised in academic cultures, one cannot deny that their legacies remain, and that black inferiority is undeniably assumed by many.

Recently, examples of this phenomenon emerged with the publishing of two racist and stereotypical articles by two separate historically white universities in the Western Cape. Both articles focused on the 'mental capabilities' of people of colour with one paper, which had been completed by a professor of research, setting out to prove that 'higher IQ's' were a contributory factor in preventing certain West African populations from falling victim to slavery. ${ }^{10}$ While the other paper, completed by students and passed through the university's Ethics board, attempted to offer 'evidence' proving that coloured women have lower mental capabilities due to biological factors such as 'smaller head size.' These reports have been denounced by various members of the academic community for being based on stereotypes, skewed data, and biased assumptions that have been long refuted. ${ }^{11}$ However, the fact that they gained support from senior members in the university system, or that ethical committees did not question the absurdity of their thesis, is proof that this longheld colonial bias has not yet fallen.

This existence of scientific racism in a contemporary society, let alone contemporary or modern-day academia, is both vexing and puzzling to many however, further refuting the claims made by these papers is not the concern of this paper. I also do not aim to prove the existence of African thought and philosophy as I believe this is obvious. I do aim, however, to explore the epistemological violence against black people in academia and demonstrate how the assumption of European superiority contributes to that narrative. Through this paper, I aim to disprove the claim that knowledge, academic thought and societal discourse are neutral and objective, as well as explore links between transformation of the university system, the teaching of law and society in general. I argue that the constitution has failed at achieving a 'free, equal and unified' South Africa despite its objectives, and that the examination of the law with a critical approach of its racially charged aspects will offer some insight into addressing deep colonial biases. ${ }^{12}$ This will be done through examining the various arguments surrounding Eurocentrism and white supremacy in academia, society and the law. ${ }^{13}$

10 Z Dano Cape Argus, 'Stellenbosch study on coloured women 'draws on colonial stereotypes' 29 April 2019 https://www.iol.co.za/capeargus/news/stellenboschstudy-on-coloured-women-draws-on-colonial-stereotypes-2216623 (accessed 29 April 2019). See also N Daniels Cape Times, 'UCT prof resigns after slavery study' 16 May 2019 https://www.iol.co.za/capetimes/news/uct-prof-resignsafter-slavery-study-23318441 (accessed 18 May 2019).

11 Wiredu (n 8) 56.

12 Sec 1 of the Constitution of the Republic of South Africa, 1996.

13 J Modiri 'The colour of law, power and knowledge' (2012) 28 SAJHR at 406. 


\section{The colonial construction of a black identity}

African thought has not only been ignored for much of history but also had its existence denied. To colonial scholars, the ability to record history or the existence of the concept of a history at all in South Africa was deemed not to exist before European arrival in $1652 .^{14}$ Furthermore, colonial scholarship was characterised by copious scientific and anthropological studies set out to prove that African people did not possess the tools necessary for academic thought of substance. African languages were considered either absent altogether or, at least, at too 'primitive' a level to be of academic significance. This systematic denial of thought and academia has not only painted a vision of Africa as the 'Dark Continent' in need of European intervention and enlightenment, but it also sets out to prove that African people exist as 'sub-human' beings. ${ }^{15}$

Though mostly known as a leading figure in Euro-American philosophy, Kant set out to prove such a theory in his various anthropological and geographical studies. He argued that each person from each race is born with a level of capability to think rationally and that African people, though possessing the capability to learn certain skills in what he calls 'training,' do not possess the capabilities to do so. Kant also makes the assertion that the act of being human is directly related to the possession of rationality and philosophical thought necessary to actualise one's existence under law. In this way, not only does Kant deny the possibility of existence of African thought, but he also denies the existence of an original system of justice in Africa under which African people could exist. In this way, Kant denies African people the humanity reserved for Europeans, as well as the legitimacy of African law and morality. ${ }^{16}$

Though Kant's understanding of race has been denounced as both blatantly racist and inaccurate, it has not been completely severed from educational institutions today. White supremacy is not only left unchallenged by many, but a significant amount of effort is put into proving it. Bell notes how various studies over the years have set out to prove that some biological or scientific factor presupposes white superiority, with the immediate dismissal or denial of the contrary despite conclusive data. ${ }^{17}$ Whether racism is displayed in as blatant a setting as the basis of poverty and slavery apologist doctrines adopted by the recent studies from the Western Cape, or in the subtle

14 S Biko I write what $i$ like: A selection of his writings (1978). 76.

15 Mudimbe (n 7) 20-21.

16 EC Eze 'The Colour of Reason: The idea of “Race” in Kant's Anthropology,' in Philosophy from Africa: a text with readings (2nd ed) (eds) PH Coetzee and APJ Roux (2002) 349 \& 438.

17 D Bell 'Who's afraid of critical race theory?' (1995) University of Illinois Law Review at 899. 
treatments of black colleagues and students noted by Bell, the assumption that the identity of 'the African' is synonymous with that of inferiority, continues to plague academia. This demonstrates the residual assault of colonial subjugation on the possibility of an African academic identity.

Wiredu argues that in order to ask the question of whether African philosophy exists, one would have to approach it from a prejudiced standpoint. ${ }^{18}$ He demonstrates that, in order for one to question something's existence, one would have to consider the possibility that it does not exist, which in this case, would be the absurd possibility that African people are incapable of philosophical thought. ${ }^{19}$ While this mode of thought would question the existence of rationality and understanding of black people necessary to consider one's own affairs, it also mimics Kant's argument that black people are subhuman in comparison to white civilisation. The denial of African philosophy in this way, is a denial of African humanity that served as support for the justification of slavery and suppression of black people for centuries. 20

To a large extent, this assault on African epistemology was this basis of the thinking that colonialists used to dismiss any form of government, religion or philosophy as 'pagan' superstition or 'primitive' barbarism. ${ }^{21}$ This allowed the justification of colonial patriarchal rule in which black people were seen as incapable of running their own governments and required colonial rule. ${ }^{22}$ It allowed the economic quests of the scramble for land in Africa to be obscured by seemingly noble quests of Christianisation and, in turn, 'civilization'. ${ }^{23}$ In order for this model to be successful even after the recognition of African religions and societal structures, one would need to reject the very possibility of African philosophical and scientific thought of being of equal significance to Euro-American academia. ${ }^{24}$ This is still a pattern that is observed in Western academic circles today, which not only proves the existence of deep colonial biases but also the self-defeating model of decolonialisation that has been adopted. ${ }^{25}$

Ramose argues that, not only does this exclusion of African scientific and philosophical thought from educational circles, which is

18 K Wiredu 'What can philosophy do for Africa?' in Philosophy and an African culture K Wiredu (ed) (1980) 54.

19 Wiredu (n 18) 53. See also MB Ramose 'Discourse on Africa' in Philosophy from Africa: a text with readings (2nd ed) Coetzee, PH and Roux, APJ (eds) (2002) 4.

20 Ramose (n 19) 4.

21 Ranuga (n 1) 188.

22 KR White 2009. 'Scourge of racism: Genocide in Rwanda,' Journal of Black Studies (2009) 39(3) 473. See also Mudimbe (n 7) 20-21.

23 Mudimbe (n 7) 21.

24 Wiredu (n 18) 57.

25 Ramose (n 19) 5. 
based on illogical and unsound grounds, defeat the very nature of education as a whole, however, it also contributes to a paradoxical cycle that 'de-liberates' knowledge while aiming to transform it. ${ }^{26}$ Moridiri similarly notes this paradox in the advancement of the 1996 South African Constitution and that the supposed inferior nature of African thought is, to a certain extent, identifiable in jurisprudential practice. Though South Africa has, to a large extent, turned to the law as a tool to obtain transformation, topics of justice, morality and race are though not only isolated to a single, optional module, often fail to consider African thought surrounding these concepts. ${ }^{27}$ Wiredu's assessment of the contemporary educational climate echoes this observation in that, even when African philosophy is considered, it is drastically appropriated to legitimise existing euro-Christian assumptions. This focus on one set of possible answers to the achievement of justice perpetuates the colonial cycle of silencing black thought, as well as automatically assuming African inferiority.

Ramose argues that though efforts to decolonise have, on face value, removed the usurpation of the right of African people to speak for themselves, concepts of racial identity and justice are still intricately linked and cannot be ignored. ${ }^{28}$ Biko notes that the continued exclusion of African thought not only entrenches the colonisation of the mind and self-depreciation of people of colour, but that it pushes society further from the achievement of substantive justice. ${ }^{29}$ This demonstrates how the active exclusion of black thought from society is a significant factor in a system of selflegitimising illegitimate assumptions based on racist preconceptions. However, it also proves that the academic landscape is not neutral, despite the fact that race is understood to be social rather than scientific. ${ }^{30}$ One can also argue that the existence of this paradox is a manifestation of an inherently racist society that has not been defeated by the inclusion of rights-based legislation such as the Constitution.

\section{A critical approach to race and education}

Approaching the law and Constitution from the perspective of a critique is a characteristic of Critical Legal scholarship. This jurisprudential approach acknowledges that the law is constructed and used as a tool to preserve power relations that exist within the society, as well as the fact that it is, by its very nature, both political and ideological. ${ }^{31}$ Alongside the Gender Theory and Queer Theory,

Ramose (n 19) 6.

Modiri (n 5) 178.

Ramose (n 19) 6. See also Biko (n 14) 75.

Biko (n 14) 75.

30 B Hepple Equality: The new legal framework (2011) 36. 
the Critical Race Theory can be seen to mimic these acknowledgments of the charged nature of law. ${ }^{32}$ Be that as it may, the Critical Race theory places an increased emphasis on the economic and class divisions based on race that are present and perpetuated in society. Critical Race theorists critique this racist nature of the law and argue that this inherent racism is a reflection of the society in which it operates. They further argue that ignoring this property of the law plays a substantial role in the continued suppression of black people.

Jurisprudential scholars who adopt the Critical Race theory as a lens often argue that the law cannot and should not be studied in isolation. ${ }^{33}$ Many legal scholars are criticised for the continued attempt to distinguish 'pure' law from philosophical debates of justice and ethics. ${ }^{34}$ Failure to do so has been argued to result in the development of a lack of understanding of the moral implications that that law contains and a mechanical and unqualified application of the law. ${ }^{35}$ As many of these laws have been inherited from colonial and apartheid structures, many argue that this accounts for the lack of substantive change in society in post-1994 South Africa. It is for this reason that Critical Race theorists reject a restricted approach to jurisprudence and legal education and instead, encourage the law to be contextualised in its historic, political and moral contexts. ${ }^{36}$

Bell notes that inherited from its roots in the Critical Legal Studies movement, there exists both a commitment to 'radical critique of the law' at the basis of Critical Race theory, as well as an ultimate agenda of the reconstruction of the law and society in a manner that achieves the emancipation of black people. ${ }^{37}$ Though this ultimate goal is reminiscent of Civil Rights scholarship, Bell notes that Critical Race theorists dismiss claims regarding the redemptive power of rights legislation such as the Civil Rights Act. ${ }^{38} \mathrm{He}$ argues that, though the vision promised by rights legislation is one welcomed by many critical race scholars, their existence often results in the 'illusion' of equality rather than a qualitative attempt at justice owing to the non-racial structure often employed by rights legislation. ${ }^{39}$

Modiri harshly criticises the colour-blind approach to transformation often adopted by white liberals. ${ }^{40}$ This approach, also criticised by Biko, has been argued to contribute to a superficial

31 Modiri (n 5) 180.

32 J Modiri, "Towards a "post"-apartheid critical race jurisprudence: Divining our racial themes' (2012) 27 SAPL at 246.

33 D Bell (n 17) 899.

34 C Douzinas \& A Gearey Critical jurisprudence: The political philosophy of justice (2005) 5.

35 Douzinas \& Gearey (n 34) 7.

36 Douzinas \& Gearey (n 34) 3. See also Modiri (n 13) 412; Bell (n 17) 899.

37 Bell (n 17) 899.

38 Bell (n 17) 899. See also Sec 804 of the Civil Rights Act of 1964.

39 Bell (n 17) 900.

40 Biko (n 14) 69. 
transformation in which black people are, though liberated in theory, forced to enter a society that is structured to subjugate them rather than construct a new one. ${ }^{41}$ In his assessment of the constitution as a failed restorative document, Modiri recognises the extent to which a mechanical operation of blanket equality has contributed to this failure. ${ }^{42} \mathrm{He}$ argues that colonial law and structures of colonialapartheid actively sought to disempower and delegitimise the existence of African law in society in order for white economic gain. However, he also notes that these dynamics are still evident in the fact that even after the near three-decade long enactment of a values-based constitution, the juxtaposition of white privilege and black suffering is still noted in South African society. ${ }^{43}$ In this way, a mere mechanical application of the constitution to South African society has not undone the inequalities of the past but merely obscured black oppression.

Modiri further argues that the constitution, aside from ignoring past oppression, actively seeks to continue the inequality between black and white people. ${ }^{44}$ He notes the various constitutional mechanisms that prevent the radical distribution of property and the lack of access to resources faced by black people today yet ironically, such opportunities are given freely to white people. ${ }^{45}$ Furthermore, when considering concepts of justice and equality, the constitution does, to a large extent, focus solely on western models of justice and ownership with little to no consideration of African approaches to these concepts. Though the concept of Ubuntu has been recognised as integral to the theory of Transformative Constitutionalism, its use, application and understanding is paradoxical when juxtaposed with the strictly Roman and western interpretations of section 25.46 Though African Customary Law of Succession is, to a certain extent, being recognised and developed by the Constitutional Court, concepts of succession and ownership continue to be firmly European and capitalist. ${ }^{47}$ This further perpetuates the cycle of colonial apartheid and white supremacy in a document that is supposedly aimed at its overhaul. It is for this reason that Modiri notes the need for an understanding of the law's racial and political nature, as well as a commitment to radical change of the society's power dynamics.

To a certain extent, Langa's visionary Transformative Constitutionalism can be argued to mimic this concern with the morality of laws based on its values-based approach. Langa argues

42 As above.

43 As above.

44 Modiri (n 13) 408.

45 Modiri (n 13) 406.

46 P Langa 'Transformative constitutionalism' (2006) 17 Stellenbosch Law Review at 351. See also sec 25 of the Constitution of the Republic of South Africa, 1996.

47 Modiri (n 13) 408. 
that, in order for the Constitution to succeed in its transformation of society, its value of Ubuntu cannot only be adopted by courts but that they need to be the moral code to which each person is accountable. ${ }^{48}$ This approach, however, has been criticised for being too idealistic to have a tangible effect on achieving substantive justice as it affirms a state of affairs that does not exist in reality. In order for this approach of the transformation of society to be effective, it would have to be the goal of each South African to live in a society where black and white people are equal. This assumption, however, is refuted by Bell who notes that even his most liberal white colleagues have a deep-rooted fear of black success or superiority in any form. 49

Furthermore, the inclusion of a surface-level understanding of Ubuntu in the Constitution acts as an example of the appropriation of African thought for colonial convenience rather than a commitment to epistemological equality. Ubuntu as a philosophical concept has both a cultural and religious significance which is, to a large extent, ignored by the Constitution although transformative constitutionalists claim to adopt it as a value. ${ }^{50}$ By relating the values of Ubuntu to the mutual respect of one another in terms of Western concepts of property rights, whilst blatantly ignoring both its actual meaning and its significance, we are shown the extent to which African philosophy is seen as illegitimate unless it affirms European concepts of justice and morality. This view perpetuates a deep underlying assumption in the fabric of our law and society that black people are inferior.

The constitution can, in these ways, be argued to be an embodiment of the paradoxical nature of a society that supposedly values equality, yet actively seeks to defend the assumption of white superiority. The Constitution has been shown to both adopt and perpetuate the inequality that it supposedly aims to defeat in a manner that reflects the understanding of a black identity, as created by the image of Africa by European colonialists. This would reflect the argument that the law is a reflection of the values held by the society in which it operates, in as much as it would support another argument that radical change of the law will subsequently transform society.

\section{The transformation and decolonisation of knowledge production}

The continued acceptance of Europe's unilateral declaration of itself as both superior and distinct from the rest of the 'barbaric' world,

48

50 Modiri (n 13) 425. See also I Keevy 'Ubuntu versus the core values of the South African Constitution' (2009) (n 2) Journal for Juridical Science at 55. 
despite being refuted on many occasions, mimics the phenomenon of the paradoxical nature of the constitutional era. ${ }^{51}$ In tertiary education systems there exists a simultaneous juxtaposition of the assumption of white supremacy and the academic rebellion against it, which highlights the extent to which entrenched racial biases exist in society. In order to combat this phenomenon, Critical Race scholars encourage a focus on philosophy in their assessment of the value of an interdisciplinary approach to law and a general jurisprudence. Wiredu also argues that a focus on philosophy will not only lead to a better understanding of society but also to an opportunity to change it. ${ }^{52}$. In order to be successful in achieving substantive change, however, the representation of African thought in Academia is called for.

Decolonisation can be argued to be the initial step in the transformation of university spaces as it is the process of removing deeply ingrained colonial biases from thought. However, many scholars argue that this cannot be the only step taken if the damaging effects of centuries worth of racism and bias are to be corrected and substantive equality is to be achieved. ${ }^{53}$ Instead, scholars like Wiredu argue that a greater pressure should be put on academic institutions to consider issues from a variety of different perspectives rather than just one and, in doing so, accept the credibility of African scholarship. ${ }^{54}$ He also argues that philosophical thought requires the assertion of African philosophy as capable of existing in a place outside the realm of 'Western religious and metaphysical assumptions,' and, in doing so, affirm the legitimacy of African thought. 55

The advancement of the both Black Power and Black Consciousness were founded on the rebellion against intellectual subjugation. ${ }^{56}$ Biko, to a large extent, echoes these arguments in saying that, in order for black people to be truly free, black people need to emancipate themselves from the mental attitude of subservience that a white-orientated education has constructed. ${ }^{57} \mathrm{He}$ calls for the resistance of the colonial narrative of African people as barbaric and primitive through the development and practice of both African thought and African culture. ${ }^{58}$ In an echo of Fanon's argument, Biko further argues for the reclaiming of African history in a way that dismisses the colonial narrative of it being no more than

51 Ramose (n 19) 450.

52 P Chatterjee 'The nation in a heterogenous time' in The politics of the governed: reflections on popular politics in most of the world. (2004) 7. See also Wiredu (n 19) 57.

53 Wiredu (n 18) 58.

54 Bell (n 17) 897.

55 Wiredu (n 18) 55.

56 Ranuga (n 1) 183.

57 Biko (n 14) 76.

58 Biko (n 14) 77. 
'long lamentation of repeated defeats. ${ }^{59}$ In this way, the reclaiming of knowledge and scholarly resistance are highlighted as key features of substantive change. ${ }^{60}$

For centuries, African people have been made to struggle against what Mangcu labels an 'evidentiary genocide' in which formative moments in South African history have been ignored or appropriated by the media and state. ${ }^{61}$ Mangcu argues that the archive of history has been constructed to privilege certain narratives over others, and, in doing so, excludes important voices and contributions. ${ }^{62}$ At the same time, Mangcu cautions against a singular narrative of African history. ${ }^{63}$ One needs to understand the various nuances and philosophical disagreements that exist within the realm of African academia. He disproves the single narrative by examining historical inaccuracies. In this way, Mangcu argues for a critical approach not only to education but to society as a whole, as he criticises the fact that the efforts of post-1994 'nation building' are not only politically charged, but are also based on an assumption of the unequal value of particular narratives.

To a large extent, this is a key feature of Critical Race theory in that, as Bell notes, many critical race scholars adopt scholarly resistance to white privilege in the hope that this will lead to societal resistance. ${ }^{64}$ Because society is a macrocosm of the university setting and vice versa, these two intellectual spaces share a symbiotic link in which the attitudes of one are reflected in the other on a lesser or grander scale. If, as Modiri argues, the realm of tertiary education exists as a microcosm of society, approaching various academic disciplines with critical thought and a broader understanding of the power of the historical narrative can undo the deeply entrenched racist assumptions when reflected in the attitudes of the public. It is for this reason that Critical Race scholars call not only for the representation of African voices in academic discourse, but for the understanding of these narratives as equal and legitimate.

In order to truly give representation of African philosophy, Wiredu places emphasis on the importance of recognising the legitimacy of African languages. He argues that many African scholars may not even be aware of the fact that their philosophy is being impeded upon by colonial ideologies, and, in order to overcome this, African thought needs to be considered in the vernacular of African people. ${ }^{65} \mathrm{He}$

59 Biko (n 14) 76. See also Ranuga (n 1) 184.

60 Chatterjee (n 52) 7.

61 X Mangcu 'Evidentiary genocide: Intersections of race, power and the archive' in Mangcu X (eds) Becoming worthy ancestor: Archive, public deliberation and identity in South Africa (2011) 2 \&4.

62 Mangcu (n 61) 12.

63 As above.

64 Bell (n 17) 901.

65 Wiredu (n 8) 56. 
argues that this will ultimately contribute to the process of 'conceptual decolonization." 66 This will also combat the colonial assumption of language not being legitimate unless it is white. ${ }^{67}$

One cannot believe that we exist in a neutral society and, to a certain extent, this neutral society is not desirable. Bell argues that education cannot be sanitised or distilled to a single objective truth and that this truth acts as a mere mask for the agenda of perpetuating white privilege. ${ }^{68} \mathrm{He}$ argues that academia needs to be placed within its context and thus, situated within the experiences of people. ${ }^{69}$ This approach aims to close the gap between the paradoxical nature of the constitution and law and society. In this way, Critical Race academics develop a preference for a 'general jurisprudence' in which legal scholarship is not separated from various humanitarian disciplines such as those of politics and philosophy. Transforming these realms in a scholarly context has been argued to lead to actual resistance.

\section{Conclusion}

The call for transformation necessitates the acknowledgement of the context of the law and academia, and, in doing so, understanding the various nuances of and approaches to black identity in both historical and contemporary society. This society cannot be equal if one group of people need to work much harder than their white counterparts, in order to have their existence legitimised and their success recognised. Furthermore, conceptions of a shared identity or task of building a nation based on equality cannot exist while groups of people are silenced. For these reasons, despite constitutional assurances of the contrary, both the South African academic landscape and society cannot be described as free or equal, but instead, as encompassing a deep colonial bias.

Academia, legal scholarship and the law in general are innately linked to the power dynamics that exist within societal structures. Though there has been a call for the transformation of these various realms of society, the advancement of the Constitution has not done away with the faulty assumptions of scientific racism and black inferiority in the face of European thought. The only way to undo this inherent racism of South African and global societies is to approach historic and philosophical discourse critically, with as much acknowledgement of silent voices as those who take it upon themselves to portray the narrative. ${ }^{70} \mathrm{It}$ is for this reason that Critical

66 Wiredu (n 8) 59

67 Mudimbe (n 7) 57.

68 Bell (n 17) 901.

69 As above.

70 Mangcu (n 61) 12. 
Race scholarship is not only a benefit to academic and legal studies but a necessity for the substantive transformation of society and the achievement of justice. 